\title{
Normal Lung Ventilation/Perfusion Scintigraphy in Miniature Pigs
}

\author{
Se Eun Kim, Ho Jae Han and Kyung Mi Shim* \\ College of Veterinary Medicine, Channam National University, Gwangiu 500-757, Korea \\ ${ }^{1}$ Department of Radidogy, Nambu University, Gwangju 506-706, Korea
}

Received October 14, 2010 /Accepted November 17, 2010

\begin{abstract}
Miniature pigs are widely used in experiments related to pulmonary disease because of their similarities with humans. However, there are not enough data about normal lung function in miniature pigs. Thus, in this study, we investigated normal lung function in miniature pigs with lung ventilation/perfusion scintigraphy and evaluated the availability of this method. Three male miniature pigs weighing 30-35 kg were used. After general anesthesia, ventilation scintigraphy was performed with $100 \mathrm{MBq}$ of ${ }^{99 \mathrm{~m}} \mathrm{Tc}$-pertechnetate $\left(\mathrm{O}_{4}^{-}\right)$, after which perfusion scintigraphy was performed with intravenous injection of ${ }^{99 m}$ Tc-macro aggregated albumin (MAA). The functional contribution of the right lung was about $55 \%$, and left lung was about $45 \%$, similar to humans. Lung ventilation/perfusion scintigraphy was very useful in evaluating the normal lung function of miniature pigs because it was a non-invasive procedure (no tissue damage was involved), took a short time and was easy to perform. In conclusion, miniature pigs are similar to humans in functional contributions of the lung, and this method will be helpful in future pulmonary disease studies involving miniature pigs.
\end{abstract}

Key words : ${ }^{99 \mathrm{~m}} \mathrm{Tc}$-pertechnetate, ${ }^{99 \mathrm{~m}} \mathrm{Tc}$-macro aggregated albumin, lung ventilation-perfusion scintigraphy, miniature pig

\section{서 론}

폐색전증은 흔한 질병임에도 불구하고 진단이 어려운 경우 가 많으며[12], 사망률이 높은 질환 중 하나로 Pavan 등[13] 과 Kasper 등[5]에 의하면 치료를 받을 시에 사망률이 $8 \%$ 정도 되나, 적절한 치료를 받지 못하는 경우 사망률은 $18-35 \%$ 까지 이르게 된다고 보고하고 있다. 폐색전증을 진단하기 위해서는 흥부 방사선 촬영, 심전도, 동맥혈가스분석 검사 등이 있으나 이 방법들은 확진을 내릴 수 있을 정도의 민감도나 특이성이 없다고 보고되고 있으며, 폐색전증의 확실한 진단법인 폐동맥 조영술은 침습적이라는 단점이 있다[10]. 그에 비해 폐 환기/관 류 신티그라피(Ventilation/perfusion scintigraphy; SCINT)는 비침습적이라는 장점과 함께 시행하기 쉬우며 높은 민감도와 낮은 방사선조사 및 비용으로 인해 폐색전증을 진단하는 데 있어 선호되는 방법이다[3,9]. 또한 이 진단법은 폐이식을 위한 환자의 평가 및 이식 후의 폐기능 평가에도 사용되며 이식 전 폐색전증의 유무를 확인하고 부분적인 환기와 관류 이상의 정도를 평가할 수 있게 해 준다[17].

미니돼지는 유전적으로 조작하기가 편하여 이종장기이식 에서 많이 사용되고 있으며 여러 장기가 사람과 유사하다는 장점이 있어 심혈관계, 피부, 비뇨기 및 소화기와 관련된 실험 에서 많이 쓰이고 있다[15]. 특히 호흡기와 관련된 실험에서는

*Corresponding author

Tel : +82-62-970-0160, Fax : +82-62-972-6200

E-mail : kmshim@nambu.ac.kr
폐렴[8], 폐색전증[2], 천식[6] 및 약물을 이용한 급성 폐손상 등과 같은 질환에 많이 사용되고 있다.

본 연구에서는 미니돼지에서 폐 환기/관류 신티그라피를 실시하여 정상적인 미니돼지의 폐기능 평가 및 미니돼지에서 의 폐 환기/관류 신티그라피 유용성을 평가해 보고자 하였다.

\section{재료 및 방법}

\section{실험동물}

실험동물은 PWG Genetics Korea 사의 수컷 미니돼지 (30-35 kg) 3마리를 사용하였다. 실험 전 일주일의 적응기간 동안 사육환경은 온도 $23 \pm 2{ }^{\circ} \mathrm{C}$, 상대습도 $55 \pm 10 \%$ 로 유지하였 으며 충분한 양의 사료와 물을 공급받으면서 사육되었다. 동 물의 사육과 실험은 전남대학교 동물실험 지침에 따라 수행되 었다(CNU IACUC-YB-R-2008-29).

\section{실험동물의 마취}

미니돼지는 실험 12 시간 전에 절식 및 절수를 실시하였으 며, 전마취는 xylazine (럼푼 ${ }^{\circledR}$, 바이엘코리아, 대한민국) 2.2 $\mathrm{mg} / \mathrm{kg}$ 과 tiletamine/zolazepam (Zoletil $50^{\circledR}$, 버박코리아, 대 한민국) $5 \mathrm{mg} / \mathrm{kg}$ 을 합제하여 근육주사 하였다. 그 후 이정맥 에 정맥라인을 확보하고 atropine (황산아트로핀 ${ }^{\circledR}$, 제일제약, 대한민국) $0.05 \mathrm{mg} / \mathrm{kg}$ 을 정맥으로 천천히 투여하였으며, propofol (아네폴 ${ }^{\circledR}$, 하나제약, 대한민국) $0.2 \mathrm{mg} / \mathrm{kg} / \mathrm{hr}$ 를 일정속 도주입법으로 정맥주사하여 마취를 유지하였다. 


\section{${ }^{99 m} \mathrm{TC}^{-} \mathrm{O}_{4}{ }^{-}$를 이용한 폐환기 신티그라피}

마취 후 미니돼지를 복와위로 보정하고(Fig. 1), 삽관을 실 시한 후 ambu bag과 연결하였다. 그 후 기관내 관과 Technegas generator (Tetley Manufacturing, Sydney, Australia)와 연결 하였고, Technegas ${ }^{~}{ }^{99 \mathrm{~m}} \mathrm{Tc}^{\mathrm{T}} \mathrm{O}_{4}^{-} 100 \mathrm{MBq}$ 을 ambu bag으로 인 공환기를 실시하면서 미니돼지의 폐 안으로 흡입시켰다. 동시 에 Dual head 감마카메라(GE Infinia Hawkeye)를 사용하여 정적영상(static image)을 획득하였다. 그리고 정적영상의 매 트릭스 크기는 모두 $64 \times 64$ 로 설정하였으며, 촬영은 돼지의 전 면, 후면 및 양측후사면에서 실시하였다.

\section{${ }^{99 m} \mathrm{TC}-\mathrm{MAA}$ 를 이용한 폐관류 신티그라피}

위의 폐환기 신티그라피를 실시한 후, 바로 $30 \mathrm{MBq}$ 의 ${ }^{99 \mathrm{~m}} \mathrm{Tc}$-macroaggregated albumin (MAA)를 이정맥으로 일시 주사 하였고 즉시 생리식염수 $2 \mathrm{ml}$ 를 주사하여 정적영상을 획득하였다. 영상의 매트릭스 크기는 $64 \times 64$ 로 설정하였으며 촬영은 위와 동일하게 실시하였다.

\section{결과 및 고찰}

미니돼지에서 환기/관류 신티그라피를 실시한 결과 환기 스캔에서는 기능적 분포는 왼쪽 폐가 $44.2 \%$, 오른쪽 폐에서는 $56.2 \%$ 로 나타났으며, 관류스캔에서는 왼쪽 폐가 $46.87 \%$, 오른 쪽 폐가 $54.97 \%$ 임을 확인할 수 있었다(Table 1). 이 결과를 토대로 정상돼지에서의 폐 신티그라피 상에서 왼쪽 폐보다 오른쪽 폐로의 기능적 분포가 더 큰 것을 확인할 수 있었으며, 이는 사람에서 폐용적이 오른쪽이 $55 \%$, 왼쪽이 $45 \%$ 인 것과 유사함을 알 수 있었다[7]. 또한 폐 신티그라피 사진에서도 환 기스캔과 관류스캔의 모양이 거의 일치하여 보이는 것을 확인 할 수 있었다(Fig. 2).

폐 관류스캔은 폐의 모세혈관보다 더 큰 입자들을 정맥 내 로 주입하여 혈액과 잘 섞이게 되면 국소 혈류분포와 비슷하 게 되므로 이를 통하여 폐색전증을 진단하는 방법으로, 관류

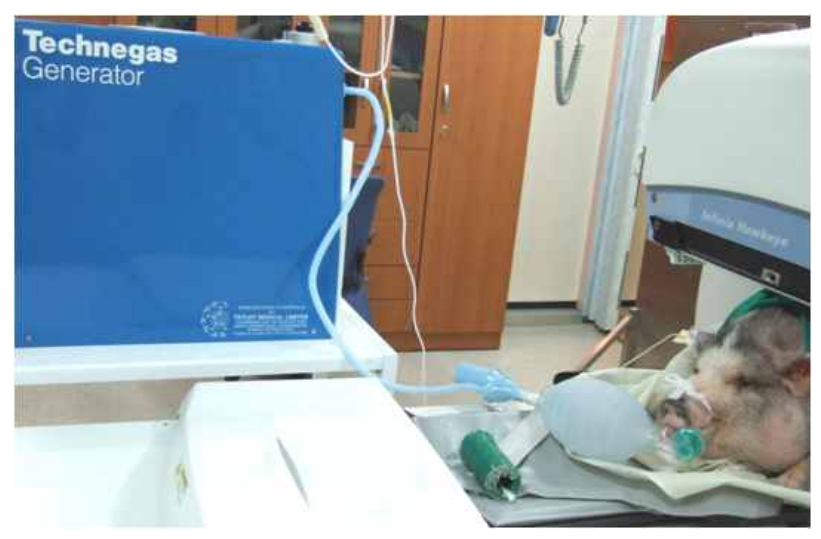

Fig. 1. A miniature pig was positioned dorso-ventrally for lung ventilation scintigraphy.
Table 1. The comparison with ventilation and perfusion scintigraphy in miniature pigs

\begin{tabular}{llcc}
\hline & & Left lung (\%) & Right lung (\%) \\
\hline \multirow{4}{*}{ Ventilation } & Upper & $9.87 \pm 4.05$ & $15.07 \pm 2.8$ \\
& Middle & $24.53 \pm 3.26$ & $28.63 \pm 4.35$ \\
& Lower & $9.43 \pm 2.31$ & $12.43 \pm 1.07$ \\
& Total & $44.2 \pm 6.14$ & $56.2 \pm 6.1$ \\
\hline \multirow{3}{*}{ Perfusion } & Upper & $7.23 \pm 1.80$ & $11.05 \pm 3.68$ \\
& Middle & $27.3 \pm 3.5$ & $28.24 \pm 2.97$ \\
& Lower & $10.47 \pm 2.35$ & $12.95 \pm 1.56$ \\
& Total & $46.87 \pm 3.67$ & $54.97 \pm 6.05$ \\
\hline
\end{tabular}

Values are expressed in mean \pm S.D.

스캔에는 주로 ${ }^{99 \mathrm{~m}} \mathrm{Tc}-\mathrm{MAA}$ 가 많이 사용된다[7]. 그러나 폐색 전증 외의 다른 폐질환에도 관류결손이 있을 수 있으므로 관 류스캔의 특이도를 높이기 위해 환기스캔을 실시하여 다른 질환과의 감별진단을 해야 한다[7]. 환기스캔에 사용되는 방사 성가스는 ${ }^{133}$ Xenon, ${ }^{133} \mathrm{Krypton},{ }^{99 \mathrm{~m}} \mathrm{Tc}$-diethylenetriamine penta-acetic acid (DTPA) 및 ${ }^{99 \mathrm{~m}} \mathrm{Tc}-\mathrm{O}_{4}^{-}$등이 있으며, ${ }^{133} \mathrm{Xenon}$ 과 ${ }^{133} K r y p t o n$ 은 비싸다는 단점이 있어 최근에는 잘 사용되지 않 는다[4]. ${ }^{99 \mathrm{~m}} \mathrm{Tc}-\mathrm{DTPA}$ 는 방사성연무로 위의 두 방사성가스보 다는 비싸지 않으나 입자의 크기가 크고 균일하지 못하여 만 성 폐색성 폐질환에서는 중심부 기도에 많이 침착되나 폐주변 부로의 침투가 잘 안 되는 문제점이 있다[16]. 반면 ${ }^{99 \mathrm{~m}} \mathrm{Tc}^{-\mathrm{O}_{4}}$ 는 ${ }^{99 \mathrm{~m}} \mathrm{Tc}$ 로 표지된 미세한 탄소구조물이 현탁되어 흡입 시 가스 와 거의 동등한 정도의 침투력으로 폐 심부까지 들어가 폐포 벽에 침착된다[14]. ${ }^{99 \mathrm{~m}} \mathrm{Tc}-\mathrm{O}_{4}{ }^{-}$는 또한 ${ }^{133} \mathrm{Xe}$ 과 비교하였을 때 영 상의 질이 높았으며, 사람에서 한 번의 흡입으로도 영상을 얻 기에 충분한 방사성 입자가 들어갈 수 있고, 다른 방사성가스 에 비해 호흡곤란증이 있는 환자들에 적용할 수 있다는 장점 이 있다[4]. ${ }^{99 \mathrm{~m}} \mathrm{Tc}-\mathrm{DTPA}$ 를 사용해서 영상을 얻을 시에는 $10-20$ 분간의 흡입을 하여야 하나 본 실험의 환기스캔에서 사용한 ${ }^{99 \mathrm{~m}} \mathrm{Tc}-\mathrm{O}_{4}{ }^{-2}$ 는 몇 번의 인공환기로도 방사성가스를 충분히 공급 할 수 있었고, 그에 따른 시간 절약으로 미니돼지 마취의 부담 을 줄일 수 있었다. 그리고 미니돼지를 움직이지 않고 연속하 여 관류 스캔을 시작할 수 있어 동일한 부위에 대한 이미지를 얻을 수 있다는 장점이 있었다[16].

또한 본 실험에서는 매트릭스의 크기를 $64 \times 64$ 로 설정하였 다. 이는 Palmer [11] 등에 의하면 매트릭스의 크기가 $128 \times 128$ 로 설정했을 때 $64 \times 64$ 와 비교 시 고해상도이기 때문에 영상획 득 시간이 2 배로 걸리거나 방사성가스와 방사성의약품의 용 량을 2 배로 늘려야 되므로 환자에 부담이 갈 가능성이 있어 $64 \times 64$ 의 매트릭스 크기가 적당하다고 보고하였다. 최근 폐색 전증 및 다른 폐질환을 진단하는데 있어 나선형 단층촬영도 많이 실시되고 있으나 가양성 및 가음성의 결과가 유출될 수 도 있다는 단점이 있다. 또한 Baile [1] 등의 연구에서는 돼지의 폐정맥에 methacrylate cast를 사용하여 폐색전증 유발 시 


\section{Ventilation}
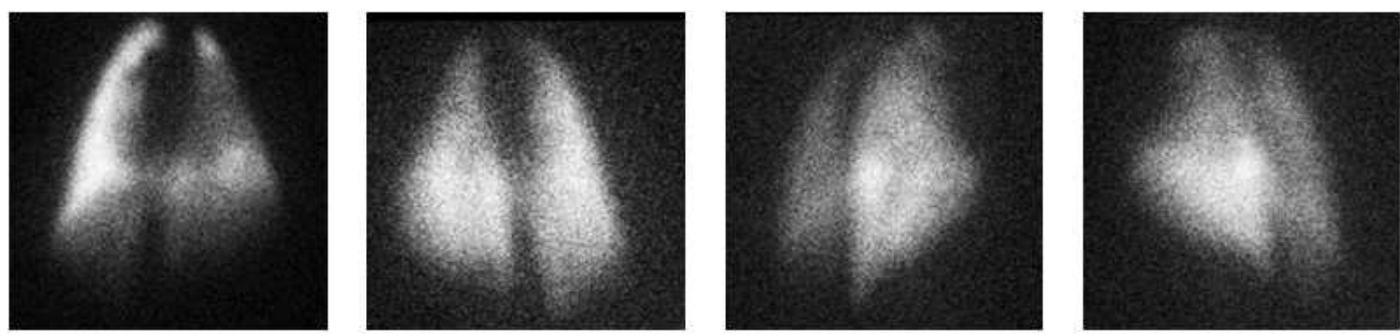

\section{Perfusion}

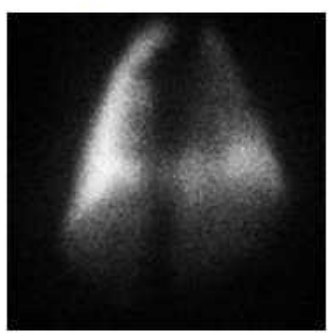

Anterior

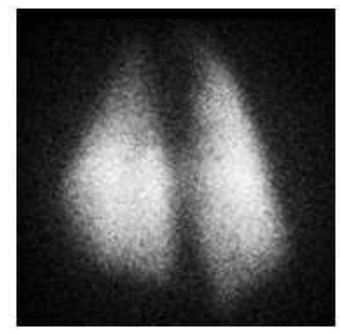

Posterior

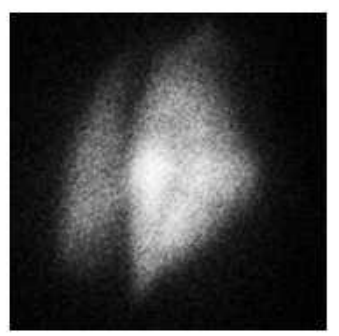

RPO

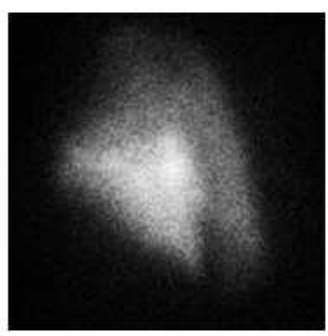

LPO

Fig. 2. Normal static images in a miniature pig after ventilation and perfusion scintigraphy with ${ }^{99 \mathrm{~m}}$ Tc-pertechnetate and ${ }^{99 \mathrm{~m}}$ Tc-macro aggregated albumin, respectively. RPO: right posterior oblique, LPO: Left posterior oblique.

$87 \%$ 만의 민감도를 보였다고 보고하고 있다. 그에 비해 Palmer [11]등의 연구에서는 폐 환기/관류 신티그라피가 임상 적으로 적절한 진단법이며 검사시간이 짧고 가격이 낮으며 낮은 방사성의약품이나 방사성가스의 용량을 적게 사용할 수 있는 장점을 가지고 있는 진단법이라 하였으며, 돼지에서 색 전을 이용한 폐색전증에서 작은 부분의 결손의 위치까지 진단 할 수 있었다고 보고하였다[2].

따라서 미니돼지에서의 폐색전증을 포함한 폐질환 관련 실 험 시 폐 환기/관류 신티그라피가 폐기능을 평가하는 데 있어 유용할 것으로 생각되며 본 연구가 미니돼지의 정상 폐기능에 관련된 정보를 제공할 수 있을 것으로 생각된다.

\section{감사의 글}

본 연구는 농촌진흥청 바이오그린 21 사업의 연구비 (Code\#20070401034006) 지원을 받아 수행되었으며 이에 감사 드립니다.

\section{References}

1. Baile, E. M., G. G. King, N. L. Muller, Y. D'Yachkova, E. E. Coche, P. D. Paré, and J. R. Mayo. 2000. Spiral computed tomography is comparable to angiography for the diagnosis of pulmonary embolism. Am J. Respir. Crit. Care Med 161, 1010-1015.
2. Bajc, M., U. Bitzén, B. Olsson, V. Perez de Sá, J. Palmer, and B. J. Jonson. 2002. Lung ventilation/perfusion SPECT in the artificially embolized pig. Nucl. Med 43, 640-647.

3. Burkill, G. J., J. R. Bell, and S. P. Padley. 1999. Survey on the use of pulmonary scintigraphy, spiral CT and conventional pulmonary angiography for suspected pulmonary embolism in the British Isles. Clin. Radiol. 54, 807-810.

4. Choi, Y. H., S. E. Kim, D. S. Lee, J. K. Chung, M. C. Lee, K. Y. Kim, C. S. Koh, and S. S. Koong. 1990. Comparison of lung ventilation scan using technegas and ${ }^{99 \mathrm{~m}}$ Tc-DTPA aerosol. Korean J. Nucl. Med 24, 237-243.

5. Kasper, W., T. Meinertz, B. Henkel, D. Eissner, K. Hahn, T. Hofmann, A. Zeiher, and H. Just. 1986. Echocardiographic findings in patients with proved pulmonary embolism. Am Heart J. 112, 1284-1290.

6. Kirschvink, N. and P. Reinhold. 2008. Use of alternative animals as asthma models. Curr. Drug Targets 9, 470-484.

7. Koh, C. S. 1997. Nuclear medicine, pp. 421-438, 2nd eds., Korea Medical Book Publisher, Seoul.

8. Luna, C. M., O. Sibila, C. Agusti, and A. Torres. 2009. Animal models of ventilator-associated pneumonia. Eur. Respir. J. 33, 182-188.

9. Maki, D. D., W. B. Gefter, and A. Alavi. 1999. Recent advances in pulmonary imaging. Chest 116, $1388-1402$.

10. Kwak, M. H., J. O. Oh, J. O. Jeong, K. C. Kim, H. S. Kim, H. C. Lee, S. C. Lee, H. C. Gwon, H. J. Kim, K. P. Hong, J. E. Park, J. D. Seo, W. R. Lee, and S. W. Park. Role of echocardiography as a screening test in patients with suspected pulmonary embolism. Korean Circulation J. 31, 
500-506

11. Palmer, J. U. Bitzén, B. Jonson and M. J. Bajc. 2001. Comprehensive ventilation/perfusion SPECT. Nucl. Med 42, 1288-1294.

12. Park, B. J., P. W. Park, Y. M. Shim, Y. T. Lee, K. H. Park, J. G. Kim, W. S. Kim, and K. I. Sung. 2009. Pulmonary embolectomy for treatment of pulmonary embolism. Korean J. Thorac. Cardiovasc. Surg. 42, 492-496.

13. Pavan, D., G. L. Nicolosi, F. Antonini-Canterin, and D. Zanuttini. 1998. Echocardiography in pulmonary embolism disease. Int. J. Cardiol. 65, S87-S90.

14. Rimkus, D. S. and W. L. Ashburn. 1990. Lung ventilation scanning with a new carbon particle radioaerosol (Technegas). Preliminary patient studies. Clin. Nucl. Med 15, 222-226.

15. Smith, A. C. and M. M. Swindle. 2006. Preparation of swine for the laboratory. ILAR J. 47, 358-363.

16. Sullivan, P. J., W. M. Burke, W. M. Burch, and F. E. Lomas. 1988. A clinical comparison of Technegas and xenon-133 in 50 patients with suspected pulmonary embolus. Chest 94 , 300-304.

17. Tiel-van Buul, M. M. C. and J. F. Verzijlbergen. 2004. Ventilation-perfusion lung scintigraphy. Imaging Decisions 4, 3-14.

초록 : 미니돼지에서 정상 폐 환기/관류 신티그라피

김세은 · 한호재· 심경미 ${ }^{1} \star$

(전남대학교 수의과대학, ${ }^{1}$ 남부대학교 방사선학과)

미니돼지에서 폐 환기/관류 신티그라피를 실시한 결과 환기스캔에서는 기능적 분포는 왼쪽 폐가 $44.2 \%$, 오른 쪽 폐에서는 $56.2 \%$ 로 나타났으며, 관류스캔에서는 왼쪽 폐가 $46.87 \%$, 오른쪽 폐가 $54.97 \%$ 임을 확인할 수 있었고 사람의 폐용적과 유사한 결과를 보임을 확인할 수 있었다. 또한 다른 방사성가스보다 짧은 시간을 필요로 하며 기계적 환기로도 스캔이 가능한 Technegas로 환기 스캔을 실시하여 미니돼지의 마취시간을 줄 일 수 있었으며 미니돼지에서 더 용이하게 폐기능을 측정할 수 있었다. 따라서 본 연구를 통해 폐 환기/관류 신티그라피가 미니 돼지에서 정상 폐기능 및 폐질환과 관련된 실험을 할 때 폐기능을 측정하는 좋은 진단법이 될 수 있으며 미니돼 지의 정상 폐기능에 관한 연구가 앞으로 폐질환과 관련된 미니돼지의 실험에 대한 정보를 제공할 수 있으리라 생각된다. 